\title{
Weight and vaginal opening in the albino rat
}

\author{
D. Frances Edwards and R. Kay* \\ Departments of Physiology and *Probability and Statistics, The University, Western Bank, \\ Sheffield S10 2TN, U.K.
}

\begin{abstract}
Summary. The body weight of rats at spontaneous vaginal opening $\left(W_{v o}\right)$ was related to the weight at weaning $\left(W_{w}\right)$ and the time elapsed between the two events $\left(t_{v o}\right)$ by the following equation:

$$
\mathrm{W}_{\mathrm{vo}}=a_{\mathrm{j}}+b \mathrm{~W}_{\mathrm{w}}+c t_{\mathrm{vo}}+\text { residual }
$$

where $a_{\mathbf{j}}$ is the litter effect present when both the male and female young are reared together. When only female young are raised, $a_{\mathrm{j}}$ may be replaced by $a$, so that in this instance there is no litter effect.
\end{abstract}

Further model differences were noted for young raised under different conditions.

\section{Introduction}

Kennedy \& Mitra (1963a, b) investigated the relationship between the mean body weight at vaginal opening and the mean time to reach vaginal opening in the rat as well as the mean weight and the mean time at the first oestrus and mating. In addition, some rats were subjected to different dietary regimens (before and after weaning), so that the effects of underfeeding on growth and sexual development could be separately assessed. Kennedy \& Mitra (1963b) thoroughly mixed the young of several litters at birth and reassociated them into small litters ( 3 young) or large litters (15-17 young): the number of females in each new group was not specified. At weaning rats from small litters each weighed $40 \mathrm{~g}$ on average and from large litters each weighed 15-25 g on average. Postweaning food was not restricted. Further young were raised in non-manipulated litters until weaning; post-weaning food was restricted in these rats. All groups reached vaginal opening. at a different mean weight and mean age, those raised in small litters being heaviest and youngest at vaginal opening. However, because the litters were mixed there are physiological and statistical problems of interpretation.

The present studies were undertaken to re-examine the relationship between weight at vaginal opening and weight at weaning and the time elapsed between the two events. The weight at weaning is included as Kennedy \& Mitra (1963b) reported it, although not in detail. We investigated these variables in non-manipulated litters and have re-investigated Exp. 1 of Kennedy \& Mitra (1963b) with the difference that litters were not mixed: instead the number of males in each litter was adjusted. The presence of litter effects (see $a_{\mathrm{j}}$ parameters in 'Results' section) was always investigated although in some instances these were found not to be appropriate (see $a$ parameter).

\section{Materials and Methods}

Twenty-four litters of a closed colony of Wistar rats (Sheffield strain), not subject to dietary manipulation, were weaned on Day 23 (day of birth = Day 0) and the weanling males and females were separated but kept in the same room (Vandenbergh, 1967). Litters were not mixed, which is of importance for the statistics. Rats from these 24 litters exhibiting vaginal opening at the weekend 
were not included in the analysis ( 37 rats). The results from the remaining 81 rats (exhibiting vaginal opening during the week) were analysed. No systematic bias was produced by omission of these 37 rats. Subsequently, 8 more litters (no dietary manipulation) were studied (weaned on Day 21) and always weighed and examined at weekends; again litters were not mixed.

In some further litters there was dietary manipulation before weaning: some rats were raised in small litters (male young were removed while sucking) and others were raised in large litters (using the males from the first group). These female rats were weaned on Day 21 and always weighed individually and examined at weekends. Litters were not mixed. For each animal the weight at weaning $\left(W_{w}\right)$, the weight at vaginal opening $\left(W_{v o}\right)$ and the time between weaning and vaginal opening $\left(t_{\mathrm{vo}}\right)$ were noted. Only vaginal opening was investigated and not first oestrus or first mating.

Weighing. When examined the young were individually weighed. Examination and weighing ceased when the rat had reached vaginal opening. Young of the 24 litters were weighed on a Mettler balance for which the weight could have been out by $2 \mathrm{~g}$ either way. All subsequent rats were weighed on a Mettler PE2000 balance operated by a GC302 peripheral (the latter contains an animal weighing programme and controls the main balance). The reading obtained is the average weight (taken over $5 \mathrm{sec}$ ) of the individual rat. Occasional repeat weighing sometimes produced variations of not more than $0 \cdot 3 \mathrm{~g}$. The results with the second balance confirmed absolutely the original results.

Diet and environment. All the animals had access to food and water ad libitum and were kept at $21-23^{\circ} \mathrm{C}$ (humidity 50-60\%). The lights were on from 06:00 to 18:00 h (Lehrer, 1981).

Parity. All the mothers were primigravid.

Statistical methods. Preliminary plots (see Text-fig. 1 and 'Results') suggested that $\mathrm{W}_{\mathrm{vo}}$ was approximately linearly dependent upon $\mathrm{W}_{\mathrm{w}}$ and $t_{\mathrm{vo}}$ and multiple linear regression analysis (Draper \& Smith, 1981) was used to assess the nature and strength of this dependence. It was not assumed that different litters were homogeneous with regard to $W_{v o}$ although it was subsequently found that the coefficients of $W_{\mathrm{w}}$ and $t_{\mathrm{vo}}$ in the regression equation were the same for all litters. Different models were fitted to the data using the statistical package GLIM (Baker \& Nelder, 1978). Model comparisons were made using the analysis of variance $F$ test. Comparing Models $A$ and $B$ with degrees of freedom (d.f.), $d_{A}$ and $d_{B}$ respectively, and residual sums of squares (RSS), $R_{A}$ and $R_{B}$ respectively, where Model A is a special case of Model B, the F statistic

$$
\frac{R_{A}-R_{B}}{d_{A}-d_{B}} \cdot \frac{d_{B}}{R_{B}}
$$

is distributed as $F_{d_{A}}-d_{B}, d_{B}$ under the null hypothesis that the description under Model $A$ is adequate when compared to Model B. Several different sets of data corresponding to different growth conditions were investigated in similar ways.

\section{Results}

Table 1 presents the means and ranges in the data for all the rats.

The original 24 litters: dependence of $W_{v o}$ on $W_{w}$ and $t_{v o}$

Text-figure 1 is a plot of the data of the 81 values for $W_{w}$ and $W_{v o}$. Since $W_{v o}$ appeared to increase with $\mathrm{W}_{\mathrm{w}}$ and $t_{\mathrm{vo}}$ in a linear way, the dependence of $\mathrm{W}_{\mathrm{vo}}$ on $\mathrm{W}_{\mathrm{w}}$ and $t_{\mathrm{vo}}$ was assessed by multiple linear regression models (Draper \& Smith, 1981). 
Table 1. Mean \pm 1 s.e. (range) of weight at weaning $\left(W_{w}\right)$, weight at vaginal opening $\left(W_{v_{0}}\right)$ and time between weaning and vaginal opening $\left(t_{\mathrm{vo}}\right)$

\begin{tabular}{lccc}
\hline \multicolumn{1}{c}{ Group } & $\mathrm{W}_{\mathrm{w}}(\mathrm{g})$ & $\mathrm{W}_{\mathrm{vo}}(\mathrm{g})$ & $t_{\mathrm{vo}}$ (days) \\
\hline Original 24 litters & $47 \cdot 1 \pm 0 \cdot 6$ & $108 \cdot 8 \pm 1 \cdot 2$ & $14 \cdot 5 \pm 0 \cdot 4$ \\
& $(35-65)$ & $(87-146)$ & $(9-32)$ \\
Confirmatory 8 litters & $38 \cdot 8 \pm 0 \cdot 6$ & $104 \cdot 8 \pm 1 \cdot 6$ & $16 \cdot 5 \pm 0 \cdot 4$ \\
& $(30-48)$ & $(84-134)$ & $(11-25)$ \\
Large litters & $36 \cdot 3 \pm 0 \cdot 7$ & $98 \cdot 8 \pm 2 \cdot 1$ & $15 \cdot 7 \pm 0 \cdot 5$ \\
Small litters & $(25-41 \cdot 5)$ & $(81-130 \cdot 5)$ & $(11-26)$ \\
& $51 \cdot 1 \pm 1 \cdot 6$ & $106 \cdot 5 \pm 2 \cdot 2$ & $14 \cdot 3 \pm 0 \cdot 8$ \\
& $(36 \cdot 5-60)$ & $(87 \cdot 5-127 \cdot 5)$ & $(10-20)$ \\
\hline
\end{tabular}

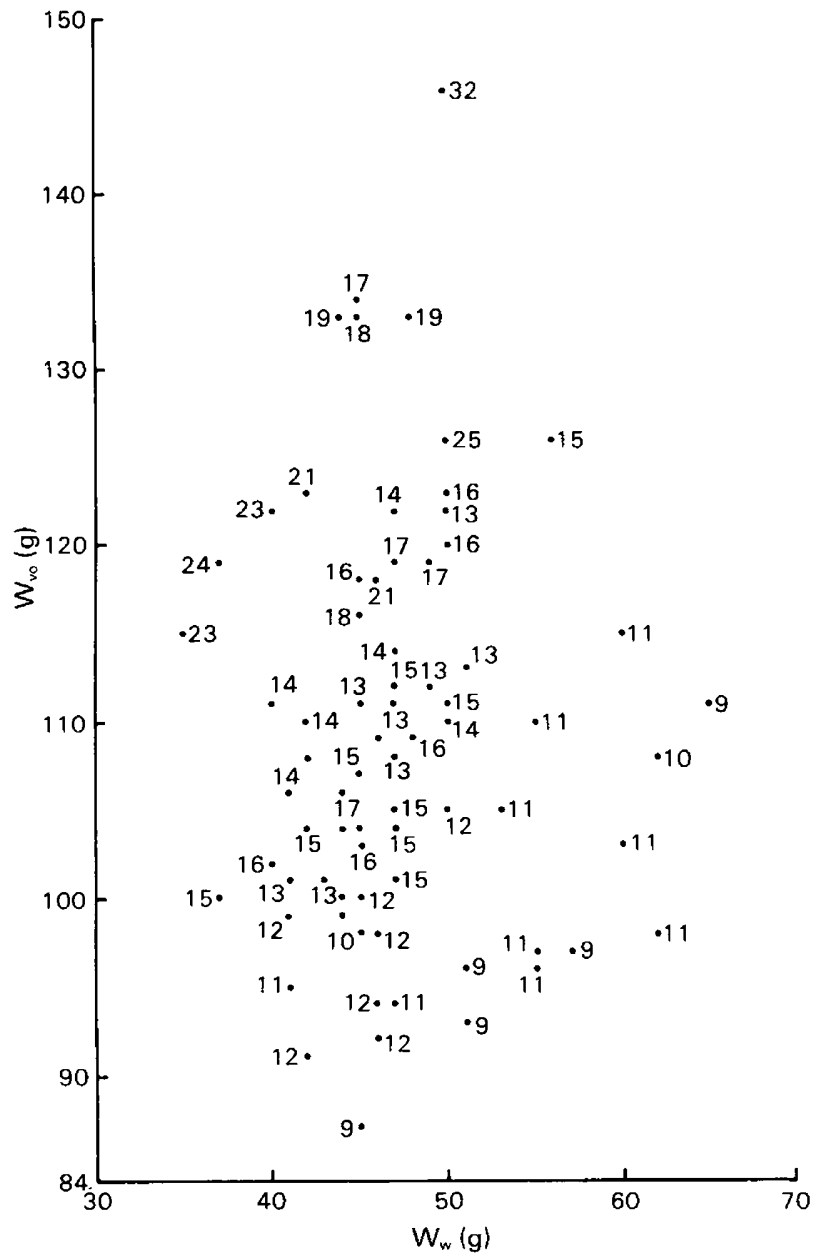

Text-fig. 1. The value of $W_{w}$ is plotted on the abscissa versus the appropriate value of $W_{v o}$ on the ordinate. Each point is annotated with the appropriate value of $t_{\mathrm{vo}}$. Thus with a $\mathrm{W}_{\mathrm{w}}$ of $50 \mathrm{~g}$, a $\mathrm{W}_{\mathrm{vo}}$ of $146 \mathrm{~g}$ the value of $t_{\mathrm{vo}}$ is 32 days. Lower values of $\mathrm{W}_{\mathrm{w}}$ tend to be associated with higher $\mathrm{W}_{\mathrm{vo}}$ and $t_{\text {vo }}$, as borne out in Text-fig. 2 . 
Table 2 presents results for the models fitted and comparisons between them. Model 1 is the analysis of covariance model, modelling the dependence of $\mathrm{W}_{\mathrm{vo}}$ on $\mathrm{W}_{\mathrm{w}}$ and $t_{\mathrm{vo}}$ allowing for baseline difference $\left(a_{\mathrm{j}}\right)$ in the litters. Models 2 and 3 respectively allow the coefficients of $t_{\mathrm{vo}}$ and $\mathrm{W}_{\mathrm{w}}$ to differ between different litters. The F statistic for comparing these models with Model 1 is shown in the final column of Table 2 . The lack of statistically significant difference suggests that the nature of the dependence of $\mathrm{W}_{\mathrm{vo}}$ on $\mathrm{W}_{\mathrm{w}}$ and $t_{\mathrm{vo}}$ can be assumed to be the same for each litter. Models 4 and 5 investigate alternative forms of the dependence of $\mathrm{W}_{\mathrm{vo}}$ on $t_{\mathrm{vo}}$. Model 5 fits both $t_{\mathrm{vo}}$ and its inverse $1 / t_{\mathrm{vo}}$ and comparison of this model with Model 1 gave an F-ratio which is not significant, thus indicating that there may possibly be some further dependence of $\mathrm{W}_{\mathrm{vo}}$ on $t_{\mathrm{vo}}$ not explained by a linear term in $t_{\mathrm{vo}}$. Fitting Model 4 , which includes $1 / t_{\mathrm{vo}}$ only produced a larger residual sum of squares than Model 1 so that $t_{\mathrm{vo}}$ is preferred to $1 / t_{\mathrm{vo}}$ alone and on this basis Model 1 was retained as an adequate description of the relationship. Model 6 fits a common litter effect, $a$, and comparison of this with Model 1 gives an F statistic which is statistically significant and so a common litter effect cannot be assumed.

Table 2. Dependence of $\mathrm{W}_{\mathrm{vo}}$ on $\mathrm{W}_{\mathrm{w}}$ and $t_{\mathrm{vo}}$ for the original 24 litters

\begin{tabular}{lrrrll}
\hline \multicolumn{1}{c}{ Model } & d.f. & RSS & Model comparison & F statistic & Significance \\
\hline (1) $a_{\mathrm{j}}+b \mathrm{~W}_{\mathrm{w}}+c t_{\mathrm{vo}}$ & 55 & 1140 & & & \\
(2) $a_{\mathrm{j}}+b \mathrm{~W}_{\mathrm{w}}+c_{\mathrm{j}} t_{\mathrm{vo}}$ & 36 & 683 & $2-1$ & $\mathrm{~F}_{19,36}=1 \cdot 27$ & $P>0 \cdot 10$ \\
(3) $a_{\mathrm{j}}+b b_{\mathrm{j}} \mathrm{W}_{\mathrm{w}}+c t_{\mathrm{vo}}$ & 33 & 766 & $3-1$ & $\mathrm{~F}_{22,33}=0 \cdot 73$ & $P>0 \cdot 10$ \\
(4) $a_{\mathrm{j}}+b \mathrm{~W}_{\mathrm{w}}+c / t_{\mathrm{vo}}$ & 55 & 1359 & $4-1$ & & \\
(5) $a_{\mathrm{j}}+b \mathrm{~W}_{\mathrm{w}}+c_{1} t_{\mathrm{vo}}+c_{2} / t_{\mathrm{vo}}$ & 54 & 1085 & $5-1$ & $\mathrm{~F}_{1,54}=2 \cdot 74$ & $P=0 \cdot 10$ \\
(6) $a+b \mathrm{~W}_{\mathrm{w}}+c t_{\mathrm{vo}}$ & 78 & 3754 & $6-1$ & $\mathrm{~F}_{23,55}=5 \cdot 48$ & $P<0 \cdot 001$ \\
\hline
\end{tabular}

To assess further the fit of Model 1 to the data, Text-figure 2 displays the residuals from the model fit. The fitted model is rearranged to give :

$$
\mathrm{W}_{\mathrm{vo}}-\hat{a}_{\mathrm{j}}-\hat{b} \mathbf{W}_{\mathrm{w}}=\hat{c} t_{\mathrm{vo}}+\text { residual }
$$

where $\hat{a}_{\mathrm{j}}, \hat{b}$, and $\hat{c}$, are estimated values.

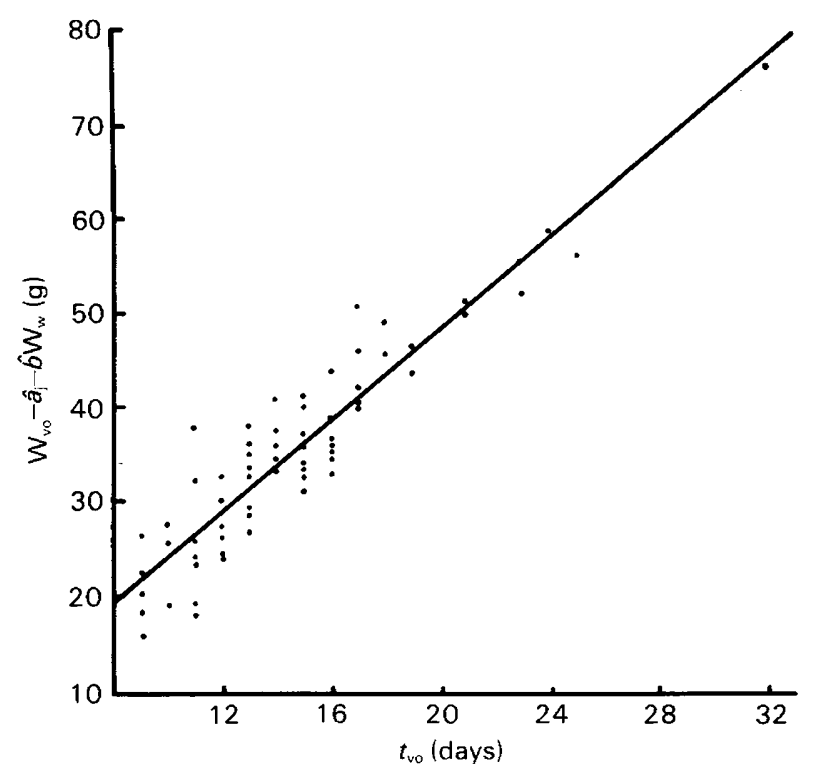

Text-fig. 2. A plot of the main data set (24 litters, 81 individuals) using the rearranged Model 1 , $\mathrm{W}_{\mathrm{vo}}-\hat{a}_{\mathrm{j}}-\hat{b} \mathrm{~W}_{\mathrm{w}}=\hat{c} t_{\mathrm{vo}}+$ residual. The residuals are plotted and the scatter is small. 
The scatter of the points from the line was small and the line therefore provided a suitable description of the data.

The values of the regression coefficients of $\mathrm{W}_{\mathrm{w}}$ and $t_{\mathrm{vo}}$ for Model 1 are given in the top line of Table 3. Comparing their values with the standard errors indicates that both $b$ and $c$ are significantly different from zero $\left(b: t_{1,55}=4.65(P<0.001) ; c: t_{1,55}=10.52(P<0.001)\right)$ and since both $\hat{b}$ and $\hat{c}$ are positive, $\mathrm{W}_{\mathrm{vo}}$ increases with increasing $\mathrm{W}_{\mathrm{w}}$ and with increasing $t_{\mathrm{vo}}$.

Table 3. Values of the estimated coefficients $b$ and $c$ for the models (see Tables 2, 4 and 5) for all the different groups of rats (see Table 1), with the standard errors of estimated coefficients shown in parentheses

\begin{tabular}{lcr}
\hline \multicolumn{1}{c}{ Sample } & $b$ & $c$ \\
\hline 24 litters & $0 \cdot 74(0.16)$ & $2 \cdot 42(0.23)^{*}$ \\
Confirmatory data (8 litters) & $1.86(0.47)$ & $3 \cdot 11(0.50)^{*}$ \\
Dietary manipulation & & \\
(a) small litters & $0.80(0.17)$ & $-536(69) \dagger$ \\
(b) large litters & $1.53(0.48)$ & $4.54(1.03)$ \\
& & $-1.05(1.43)$ \\
& & $5.68(1.29)$ \\
& & $3.28(0.49)$ \\
& & $-3.02(5 \cdot 13)$
\end{tabular}

* Model contains different $a_{\mathrm{j}}$ coefficients.

$\dagger$ Model contains $1 / t_{\mathrm{vo}}$.

$\ddagger c$ is not constant.

\section{Confirmatory data}

A further 8 litters ( 41 observations) were investigated under conditions similar to those for the original 24 litters. Table 3 presents the coefficients for Model 1 for these data. Their values are in the same direction as those for the original data although the value of $\hat{b}$ is larger. Both coefficients $(b$ and $c$ ) are significantly different from zero for the new data and these results confirm the effects noted above.

\section{Large litters (extra male young added)}

Table 4 presents the model-fitting results for these data ( 5 litters, 27 observations). Model comparisons are similar to those in Table 2 and the most appropriate model is Model 2 which allows the dependence on $t_{\mathrm{vo}}$ to vary from litter to litter. Further details for Model 2 are given in Table 3. Two of the litters gave negative values for $c_{\mathrm{j}}$ and this may seem surprising. The standard errors, however, are large in these cases and the 2 coefficients are not significantly different from zero.

Table 4. Dependence of $\mathrm{W}_{\mathrm{vo}}$ on $\mathrm{W}_{\mathrm{w}}$ and $t_{\mathrm{vo}}$ for 5 large litters

\begin{tabular}{cccccc}
\hline Model & d.f. & RSS & Model comparison & F statistic & Significance \\
\hline (1) $a_{\mathrm{j}}+b \mathrm{~W}_{\mathrm{w}}+c t_{\mathrm{vo}}$ & 20 & 703 & & & \\
(2) $a_{\mathrm{j}}+b \mathrm{~W}_{\mathrm{w}}+c_{\mathrm{j}} t_{\mathrm{vo}}$ & 16 & 359 & $2-1$ & $\mathrm{~F}_{4,16}=3.83$ & $P<0.05$ \\
(3) $a_{\mathrm{j}}+b_{\mathrm{j}} \mathrm{W}_{\mathrm{w}}+c_{\mathrm{j}} t_{\mathrm{vo}}$ & 12 & 354 & $3-2$ & $\mathrm{~F}_{4,12}=0.04$ & $P>0 \cdot 10$ \\
\hline
\end{tabular}


Small litters (females only raised)

Table 5 gives the model-fitting results for this data set ( 5 litters, 21 observations). The best model is

$$
\mathrm{W}_{\mathrm{vo}}=a+b \mathrm{~W}_{\mathrm{w}}+\frac{c}{t_{\mathrm{vo}}}
$$

The nature of the dependence on $t_{\mathrm{vo}}$ has changed and there are now no differences between the litters as regards baseline $W_{v o}$ measurements. Table 3 gives coefficient values for this model.

Table 5. Dependence of $\mathrm{W}_{\mathrm{vo}}$ on $\mathrm{W}_{\mathrm{w}}$ and $t_{\mathrm{vo}}$ for 5 small litters containing only females

\begin{tabular}{lrcclc}
\hline Model & d.f. & RSS & Model comparison & F statistic & Significance \\
\hline (1) $a_{\mathrm{j}}+b \mathrm{~W}_{\mathrm{w}}+c t_{\mathrm{vo}}$ & 14 & 352 & & & \\
(2) $a_{\mathrm{j}}+b \mathrm{~W}_{\mathrm{u}}+c / t_{\mathrm{vo}}$ & 14 & 328 & $2-1$ & & \\
(3) $a_{\mathrm{j}}+b_{\mathrm{j}} \mathrm{W}_{\mathrm{w}}+c_{\mathrm{j}} / t_{\mathrm{vo}}$ & 7 & 171 & $3-2$ & $\mathrm{~F}_{7,7}=0 \cdot 92$ & $P>0 \cdot 10$ \\
(4) $a+b \mathrm{~W}_{\mathrm{w}}+c / t_{\mathrm{vo}}$ & 18 & 458 & $4-2$ & $\mathrm{~F}_{4,14}=1 \cdot 39$ & $P>0 \cdot 10$ \\
\hline
\end{tabular}

\section{Discussion}

The use of multiple linear regression analysis for the original litters has demonstrated the existence of a litter effect $a_{\mathrm{j}}$ that random biological variation cannot account for. Because $a_{\mathrm{j}}$ is different for each litter, to avoid inextricably entangling the litter effect with a treatment effect (confounding in statistical terms), the litters must not be mixed when the effect of a treatment on $W_{v o}$ is investigated. For example, if there are 4 treatments (e.g. corresponding to 4 dose levels of a drug or 4 different operations) then there must be a minimum of 4 female rats in each litter and each rat in any one litter must receive a different dose or operation, so that each dose or operation is represented in each litter. Otherwise, if the same dose or operation was to be given or performed to all the rats in any one litter then the treatment effect would be confounded with the litter. Because of confounding the results of analysis would be biased. Even when the coefficient $a_{\mathrm{j}}$ can be replaced by the common litter effect (the coefficient $a$, as in small litters), it is still advisable to suspect the existence of confounding.

No adequate explanation can at present be advanced to account for $a_{\mathrm{j}}$. A plot of $a_{\mathrm{j}}$ versus the number of young raised showed no correlation. In the litters with only small numbers of females, the coefficient $a_{\mathrm{j}}$ could be replaced by the coefficient $a$, so that there is no litter effect. It is thus possible that the number of males present in some way causes the differences between litters. Variation in $a_{\mathrm{j}}$ might also result from differences in the nourishment of each fetus during pregnancy, which appears to affect the post-natal performance of the neonates (Barry, 1920; Cox, Legates \& Cockerham, 1959; Monteiro \& Falconer, 1966; Rattner, Michael \& Brinkley, 1979), but all the pregnant and post-partum females were treated identically. During the course of this study a change in diet from Oxoid to CRM nuts was made but only the first few litters were raised on Oxoid.

It has been argued that puberty is more closely related to age (Asdell \& Crowell, 1935) than weight (Kennedy \& Mitra, 1963b). We have shown that it depends on both. In the studies by Asdell $\&$ Crowell (1935) the control group of normally nourished rats had a greater spread of weight at vaginal opening than in time to vaginal opening: in the $40 \mathrm{~g}$ retarded group, weights at vaginal opening were low and more scattered than were times. Kennedy \& Mitra (1963b) studied underfed rats (before or after weaning) and found that the mean weights at vaginal opening between the different groups were statistically significantly different from each other, as was the mean time to vaginal opening. It is not entirely clear which statistical tests were used by Kennedy \& Mitra (1963b) to test the significance of weight, although analysis of variance and $\chi^{2}$ tests were used for 
testing age. Kennedy \& Mitra (1963b) concluded that weight was of greater importance than time in determining when puberty occurred because the mean body weights in all groups at the first cornified vaginal smear were not significantly different from each other whereas the time taken to reach the first cornified vaginal smear differed. However, when vaginal opening only was considered, both mean weight and mean time were statistically different between the groups.

Sexual development in female mice is known to be affected by litter size and the number of males in the litter (Drickamer, 1976). Drickamer (1976) mixed the litters and only one female was selected from each litter for the purpose of statistical analysis. Nevertheless, when the effect of the males was considered, no males or only one male in the litter induced earlier vaginal opening and first oestrus. Mean body weight at first oestrus was also variable, although it was not variable at vaginal opening. A litter size of 4 induced earlier puberty than a larger litter size, most of which could be accounted for by litter size $(22 \%)$ rather than the sex composition of the litter $(8 \%)$. At first oestrus the mean body weights were significantly different whereas at vaginal opening they were invariant (Drickamer, 1976). This contrasts with the results of Kennedy \& Mitra (1963b), although the latter employed various dietary regimens and a different statistical design.

The pre-weaning environment and genetic endowment are known to influence post-natal growth of the rat. In particular the maternal capacity to lactate is profoundly influenced by litter size (Cox et al., 1959; Ota \& Yokoyama, 1967; Nowosielski-Slepowron \& Park, 1974; Nelson \& Robison, 1976; Wurtman \& Miller, 1976). However, no litter in our study was so small that the rats failed to grow. In the small litters weaning weight usually exceeded $50 \mathrm{~g}$ (Table 1).

Social factors and population density have considerable influence upon the onset of puberty (Christian \& Davis, 1964; Sadleir, 1969). High population density will delay the onset of puberty and reduce the percentage of fecund females. In our study pre-weaning litter size never exceeded 16 young (in this cage extra males had been added) and the females (never more than 7 per litter) were reared separately, litter by litter, after weaning.

The results of the present study show that (1) weight at vaginal opening is dependent upon both weight at weaning and time from weaning to vaginal opening, with weight at vaginal opening increasing with weight at weaning and increasing time between weaning and vaginal opening; (2) different litters can produce different effects in that there is a baseline addition of weight at vaginal opening which is litter specific in some cases, as well as different magnitudes of dependence on time between weaning and vaginal opening; and (3), care must be exercised, because of (2), when comparing the effects of a treatment which may affect puberty. Treatments must be randomized within litters otherwise the treatment effect can be confounded with litters.

We thank Professor R. Loynes, Mrs G. Constable, Dr I. Dunsmore, Dr N. Fieller and Mr D. Robson from the Department of Probability and Statistics; Dr C. Knight of the Department of Pure Mathematics; and Dr G. Vickers of the Department of Applied and Computational Mathematics of Sheffield University for help, and the Staff of the Animal House, in particular, $\mathrm{Mr}$ R. Reitz, Mrs B. Giles and Mr C. Fox.

\section{References}

Asdell, S.A. \& Crowell, M.F. (1935) The effect of retarded growth upon the sexual development of rats. $J$. Nutr. 10, 13-24.

Baker, R.J. \& Nelder, J.A. (1978) General linear interactive modelling (GLIM). Release 3. Numerical Algorithms Group, Oxford.

Barry, L.W. (1920) Effect of inanition on the pregnant albino rat with special reference to the changes in relative weights of the various parts, systems and organs of the offspring. Contrib. Embryol. Carn. Instn 11, $91-136$.
Christian, J.J. \& Davis, D.E. (1964) Endocrines, behavior and population. Science, N.Y. 146, 15501560.

Cox, D.F., Legates, J.E. \& Cockerham, C.C. (1959) Maternal influence on body weight. J. Anim. Sci. 18, 519-527.

Draper, N.R. \& Smith, H. (1981) Applied Regression Analysis, 2nd edn. Wiley Interscience, New York.

Drickamer, L.C. (1976) Effect of size and sex ratio of litter on the sexual maturation of female mice. $J$. Reprod. Fert. 46, 369-374. 
Kennedy, G.C. \& Mitra, J. (1963a) Hypothalamic control of energy balance and the reproductive cycle in the rat. J. Physiol., Lond. 166, 395-407.

Kennedy, G.C. \& Mitra, J. (1963b) Body weight and food intake as initiating factors for puberty in the rat. $J$. Physiol., Lond. 166, 408-418.

Lehrer, S. (1981) Modification of vaginal opening time in rats by light-dark cycle. Lab. Anim. Sci. 31, 405-406.

Monteiro, L.S. \& Falconer, D.A. (1966) Compensatory growth and sexual maturity in mice. Anim. Prod. 8, 179-192.

Nelson, R.E. \& Robison, O.W. (1976) Effects of postnatal litter size on reproduction of female mice. J. Anim. Sci. 42, 824-830.

Nowosielski-Slepowron, B.J.A. \& Park, A.W. (1974) The criteria of litter size in relation to growth of the rat. 1. The influence of numbers. Acta morph. neerl.-scand. 12, 299-316.
Ôta, K. \& Yokoyama, A. (1967) Body weight and food consumption of lactating rats: effects of ovariectomy and of arrest and resumption of suckling. J. Endocr. 38, 251-261.

Rattner, B.A., Michael, S.D. \& Brinkley, H.J. (1979) Plasma gonadotrophins and progesterone concentrations during various degrees of underfeeding in pregnant mice. J. Reprod. Fert. 56, 587-591.

Sadleir, R.M.F.S. (1969) The Ecology of Reproduction in Wild and Domestic Mammals, Ch. 5. Methuen Co. Ltd.

Vandenbergh, J.G. (1967) Effect of the presence of a male on the sexual maturation of female mice. Endocrinology 81, 345 349 .

Wurtman, J.J. \& Miller, S.A. (1976) Effect of litter size on weight gain in rats. $J$. Nutr. 106, 697-701.

Received 25 November 1983 